\title{
LA GÉNESIS DE LA INTERSUBJETIVIDAD EN LA REIVINDICACIÓN DE FICHTE
}

\section{GENESIS OF INTERSUBJECTIVITY IN FICHTE’S RECLAMATION}

\author{
Mariano Gaudio ${ }^{1}$ \\ CONICET (Argentina)
}

Aceptado: 29/09/2016

Recibido: 20/07/2016

\begin{abstract}
Resumen: En este trabajo se intenta mostrar que los elementos para la teoría de la intersubjetividad en Fichte se encuentran en Reivindicación de la libertad de pensamiento (1793). Primero se expone el marco general de formulación del problema en la filosofía del Fichte de Jena. Luego se analiza la argumentación de la Reivindicación: la crítica al despotismo, el descubrimiento de la ley moral, la distinción entre derechos alienables e inalienables, las condiciones de libertad y personalidad, la unidad entre libertad de pensamiento y libertad de expresión, la relevancia de la comunicación y la legitimación de la autoridad. Finalmente se enfatiza lo jurídico y las perspectivas de esta intersubjetividad incipiente.
\end{abstract}

Palabras-clave: Fichte; intersubjetividad; libertad; comunicación; derecho.

\begin{abstract}
This paper attempts to show what the elements for intersubjectivity are present in Fichte's Reclamation of the Freedom of Thought (1793). First it exposed the general context of problem formulation in Fichte's philosophy in Jena. Second the Reclamation argumentation is analyzed according to critic of despotism, moral law evidence, the distinction between alienable and inalienable rights, freedom and personality as conditions, unity between freedom of thought and freedom of expression, relevance of communication, and authority's legitimization. Finally, is emphasizes the juridical and drifts for the emerging intersubjectivity.
\end{abstract}

Key-words: Fichte; intersubjectivity; freedom; communication; right.

1. (mgaudio77@yahoo.com.ar) Doctor en Filosofía. Profesor en enseñanza media y superior en Filosofía. 


\section{El Yo y la alteridad}

En una primera aproximación a la filosofía de Fichte en su etapa de Jena (entre 1794 y 1798), dos aspectos aparentemente contradictorios suelen concitar la atención en la literatura especializada: por una parte, la fundamentación de todo el saber desde un primer principio, el Yo absoluto, en el Fundamento de toda la Doctrina de la Ciencia de 1794, y su consiguiente trabazón con el No-Yo y la reciprocidad entre Yo y No-Yo finitos. Por otra parte, y en presunto contraste con lo anterior, en el Fundamento del derecho natural (1796-7) el procedimiento parece invertirse y comenzar con el ser racional finito, para luego mediante la exhortación y el reconocimiento revelar que este ser se encuentra en una comunidad jurídica. ${ }^{2}$ Mientras en el primer caso Fichte concebiría un Yo trascendental, universal, incondicionado, activo por sí mismo y enfrentado a la objetividad, en el segundo concebiría un Yo empírico, particular, condicionado, activo en virtud de la interpelación de los otros y articulado con éstos en limitaciones recíprocas. Más allá de la artificialidad de la contraposición, de ella surgen los intentos por compatibilizar y reconstruir los lazos entre la filosofía primera de Fichte (la Doctrina de la Ciencia) y su concepción jurídico-política. Aunque esta constelación de problemas nos alejan del motivo del presente trabajo, a la luz de la tensión entre fundamentación especulativa y derecho se observa la relevancia de una temática sumamente novedosa incluso para el panorama de la filosofía moderna en general: la intersubjetividad.

El tema de la intersubjetividad en Fichte, junto con el paulatino abandono de la exposición del Fundamento de toda la Doctrina de la Ciencia desde la trilogía de principios, cobra fuerza en el Derecho natural y en obras posteriores, especialmente en la Doctrina de la Ciencia nova methodo (1796 ss.) y en la Ética (1798). Pero la literatura especializada se ha concentrado en dilucidar cómo se concilia la intersubjetividad con la filosofía anterior, y en este sentido mostrar la génesis de la misma, ya sea en el Fundamento de 1794-5, ${ }^{3}$ ya sea en Algunas lecciones sobre la destinación

2. L. Siep llama la atención sobre estos dos aspectos en Praktische Philosophie im Deutschen Idealismus. Frankfurt: Suhrkamp, 1992, pp. 21-30; recogiendo motivos ya presentados en Annerkennung als Prinzip der praktischen Philosophie. Freiburg/München: Karl Alber, 1979, pp. 27-32. También R. Williams desarrolla esta contraposición y reseña las intervenciones sobre el problema en: Recognition. Fichte and Hegel on the Others. New York: State University of New York Press, pp. 49-54.

3. Los citados L. Siep y R. Williams buscan esta conciliación, el primero mediante el concepto de Wirksamkeit (Siep, L.: Praktische Philosophie cit., pp. 24-30) y el segundo mediante el

Thémata. Revista de Filosofía $\mathrm{N}^{\circ} 56$ (2017) pp.: 91-110. 
del sabio, ${ }^{4}$ también de 1794 . No obstante, las interpretaciones genealógicas suelen pasar por alto un antecedente, a nuestro entender muy importante, del desarrollo de la intersubjetividad en Fichte: la Reivindicación de la libertad de pensamiento (1793). ${ }^{5}$ La hipótesis que intentaremos sustentar es que en este opúsculo se encuentran en germen los elementos para la formulación ulterior -más completa y compleja- de la intersubjetividad. Ésta consiste en la amalgama entre sí-mismo y otro, o entre Yo y alteridad, donde la propia constitución de uno se articula en relación con el otro y viceversa; y comienza en el nivel de la finitud jurídica más concreta para luego elevarse a instancias superiores. En el Fundamento del derecho natural, la intersubjetividad descansa en los conceptos de exhortación, reconocimiento, trato libre y racional, y en la influencia recíproca a nivel corporal, todo lo cual desemboca en la comunidad jurídica. En la Reivindicación, en cambio, la dinámica de la reciprocidad sólo resulta expuesta unilateralmente, al modo de un condicional cuyo contenido implica una trabazón a desplegar.

Además, el esquema argumentativo en que se desenvuelve la alteridad constitutiva del Yo en la Reivindicación resulta similar al que Fichte presenta tanto en La destinación del sabio como en el Fundamento del derecho natural, dado que parte de la individualidad para luego mostrarla, en una secuencia de profundización y reconfiguración, en el marco de un entramado de relaciones vinculantes. Aquello que en la Reivindicación permite este articulado -y su consiguiente conexión con las formulaciones ulteriores- es la comunicación, o el compartir, que exhibe el carácter esencial del «dar y recibir», el vector relacional constitutivo de la propia personalidad. En la medida en que este relacionamiento resulta vital para la constitución de la mismidad, el otro se revela como mediación necesaria en la (con-)formación del Yo. Y este aspecto no merma, sino que potencia, la facultad de ponerse a sí mismo o, en términos propios de la Reivindicación,

concepto de Anstoss (Williams, R.: Recognition, cit., pp. 56-62). Ambas estrategias contienen dificultades, en alguna medida anticipadas por P. Baummans: Fichtes ursprünglichen System. Stuttgart-Bad Cannstatt: Frommann-Holzboog, 1972, pp. 166 ss., 176-177. Baummans también critica (pp. 171-174) la tesis de Philonenko, que asocia la intersubjetividad directamente a la Doctrina de la Ciencia de 1794 en La liberté humanine dans la philosophie de Fichte. París: Vrin, 1966; véase también: Philonenko, A.: L’Oeuvre de Fichte. París: Vrin, 1984, pp. 45-53. W. Janke, en cambio, propone otro camino de conciliación, mediado por la Doctrina de la Ciencia nova methodo: "Annerkennung. Fichtes Grundlegungen des Rechtsgrundes", en Kant-Studien, LXXXII, 1992, pp. 201-206.

4. Lauth, R.: "Le problème de l'interpersonnalité chez J. G. Fichte", en Archives de Philosophie, $\mathrm{n}^{\circ} 25,1962$, pp. 325-344.

5. Fichte, J. G.: Zurückforderung der Denkfreiheit, en J. G. Fichtes sämmtliche Werke. Hrsg. I. Fichte. Berlín: W. de Gruyter, 1971; en adelante indicamos esta edición, como es habitual, con la sigla FSW, seguida del tomo, en este caso VI, pp. 1-35. Trad. Cast. F. Oncina Coves. Madrid: Tecnos, 1986 (en adelante: RLP).

Thémata. Revista de Filosofía Nº56 (2017) pp.: 91-110. 
la transparencia, acceso y elevación a la espiritualidad, a la ley moral, o a la razón.

Pero esta secuencia se halla eclipsada por una temática sobresaliente: la crítica a la censura, en el marco de la deslegitimación completa del despotismo y en aras de un espacio público efectivamente al servicio de la Ilustración y no de la protección del poder establecido, junto con la defensa de la identidad entre libertad de pensamiento y libertad de expresión. En esta perspectiva Fichte alimenta una dimensión social-horizontal de relaciones igualitarias que entretejen incluso al príncipe. Así, la literatura fichteana suele enfatizar aspectos de esta temática (la agitación revolucionaria de los principios de libertad e igualdad, ${ }^{6}$ la libertad ética como punto de partida del progreso moral, ${ }^{7}$ la contraposición entre el sojuzgamiento despótico y la espontaneidad, ${ }^{8}$ el espacio público característico de la Ilustración, ${ }^{9}$ la coherencia de este espacio con los derechos originarios, ${ }^{10}$ etc.) $\sin$ horadar en la intersubjetividad implícita. ${ }^{11}$

\section{La intersubjetividad en la Reivindicación}

Según nuestra hipótesis inicial, las condiciones para el desarrollo de la teoría de la intersubjetividad en Fichte se encuentran germinalmente formuladas en el temprano opúsculo, Reivindicación de la libertad de pensamiento, lo que no significa que sean explicitadas en todas sus determinaciones, sino que sólo configuran un punto de partida necesario para

6. Willms, B.: Die totale Freiheit. Fichtes politische Philosophie. Köln und Opladen: Westdeutscher Verlag, 1967, pp. 18-21, 43.

7. Baummans, P.: Fichtes Wissenschaftslehre. Probleme ihres Anfangs. Bonn: Bouvier Verlag - Herbert Grundmann, 1974, pp. 57-59.

8. Duso, G.: Contradizzione e dialettica nella formazione del pensiero fichtiano. Urbino: Argalia, 1974, pp. 126-129.

9. Radrizzani, I.: "La Doctrine de la Science et l'Aufklärung", en Revue de métaphysique et de morale, $\mathrm{n}^{\circ}$ 49, 2006, p. 131.

10. Rampazzo Bazzan, M.: «Persönlichkeit und Denkfreiheit. Ein Beitrag zur Entstehung des Urrechtsbegriffs bei Fichte», en Ch. Asmuth (Hrsg.): Transzendentalphilosophie und Person. Leiblichkeit - Interpersonalität - Anerkennung. Bielefeld: Transcript Verlag, 2007, pp. 377-380.

11. Cabe destacar que C. Hunter acepta que la teoría de la interpersonalidad se encuentra en la Reivindicación, en los pasajes que analizamos aquí, pero sólo lo señala. Hunter, C.: Der Interpersonalitätsbeweis in Fichtes frührer angewandter praktischer Philosophie. Meisenheim: Verlag Anton Hain, 1973, p. 12.

Thémata. Revista de Filosofía $\mathrm{N}^{\circ} 56$ (2017) pp.: 91-110. 
el desarrollo ulterior. Aquí nos proponemos contextualizar, reconstruir y problematizar tales condiciones.

Más allá de los múltiples contrincantes (príncipes, doctos, censores, la opinión pública en general, el pueblo dormido, etc. $)^{12}$ a los cuales podría dirigirse la Reivindicación de Fichte, la polémica se alza principalmente contra la intención de legitimar el despotismo, contra todas aquellas estrategias que de una u otra manera buscan argumentos para justificar un orden esencialmente injusto. En este sentido, la alusión esporádica a Rousseau ${ }^{13}$ no es casual, así como tampoco lo es la doble alternativa de la historia de avanzar o bien mediante la revolución, o bien mediante el progreso gradual. ${ }^{14}$ Pues la inhibición de una fuerza proyectada acentúa la tensión, y del mismo modo que el dique se quiebra con la presión de agua, ${ }^{15}$ la revolución resulta inminente en la medida en que se reprime la libertad de pensamiento. La libertad de pensamiento se convierte en elemento decisivo para diagnosticar un estado de cosas.

Con aparente retórica, Fichte exhorta al pueblo a entregar todo (los hijos para la guerra, el alimento de los pobres para los animales de los ricos, o el futuro entero), pero jamás la libertad de pensamiento. ${ }^{16}$ Incluso

12. La alusión a los príncipes europeos opresores se encuentra en el subtítulo. Pero en ciertos pasajes, como veremos, esta centralidad cede su lugar a los doctos censores, los «satélites del despotismo» (FSW VI 8, RLP 11). Este aspecto concierne directamente al espacio de la opinión pública y, por ende, resulta familiar a la concepción de Kant en Respuesta a la pregunta qué es la Ilustración (1784), aunque Fichte no comparta el optimismo del uso público de la razón. Sobre el contexto histórico de la opinión pública y de la censura, véase M. Sauter: "Las luces a prueba" (trad. L. Sanz), en Istor. Revista de Historia, $\mathrm{n}^{\circ}$ 19, 2004, pp. 31-48; y del mismo autor: Visions of the Enlightenment. Leiden: Brill, 2009, pp. 105-140. Sobre el destinatario de esta obra, J. Villacañas sostiene que es la nobleza, y que Fichte caracteriza al pueblo como ciego y pasivo: "Fichte y los orígenes del nacionalismo alemán moderno", en Revista de estudios políticos (nueva época), n 72 , 1991, pp. 146-147 nota. También F. Oncina reconoce la dirección popular de la Ilustración, y en cuanto al destinatario de esta obra afirma que se trata de un híbrido: «La recepción de la Crítica del Juicio en el jacobinismo kantiano: luces y sombras en el camino hacia una teoría democrática de la Ilustración", en R. Rodríguez Aramayo - G. Vilar (editores): En la cumbre del criticismo. Barcelona: Anthropos, 1992, pp. 197-201.

13. FSW VI 5, RLP 6.

14. FSW VI 5-6, RLP 6-8.

15. La metáfora del dique (FSW VI 6, RLP 8) reaparece en Wissenschaftslehre Nova Methodo - Krause, §6, en Gesamtausgabe der Bayerischen Akademie der Wissenschaften. Hrsg. R. Lauth, H. Jacob, y otros. Stuttgart: Fromman, 1962 ss. (en adelante, como es habitual, la indicamos con la sigla GA, junto con serie/tomo), IV/3 384. En la medida en que el dique refiere a la tensión entre una fuerza y su contención, se asemeja con la metáfora del resorte en Das System der Sittenlehre, § 1, FSW IV 26-27 (trad. cast. J. Rivera de Rosales: Ética. Madrid, Akal, 2005, p. 92); y § 2, FSW IV 33-34 (trad. pp. 98-99). La inhibición u obstáculo funciona como aquello que en la tensión potencia la actividad, como la "espina que moviliza» (FSW VI 5, RLP 6).

16. FSW VI 6-7, RLP 8-9.

Thémata. Revista de Filosofía Nº5 (2017) pp.: 91-110. 
la responsabilidad de perder semejante tesoro no recae en el príncipe, sino en el pueblo mismo, que lo sobreestima y que se subestima. Esta proclama, aunque parezca panfletaria, contiene un motivo filosófico sustancial: la claudicación en la libertad de pensamiento implica la esclavitud espiritual y corporal, la dependencia no sólo en ideas y acciones del pueblo respecto del príncipe y de sus servidores, sino también y fundamentalmente de la facultad de autodeterminación. La cesión de la libertad de pensar conlleva paradójicamente la no-asunción de la libertad, o la asunción de una libertad que en ese mismo acto se niega a sí misma. Por ende, no es culpa del déspota sino del pueblo que, siendo y sabiéndose libre, no obstante en todas partes está encadenado. Y está encadenado no porque carezca de suficiente saber, ni porque sólo el príncipe sepa en qué consiste su felicidad; el pueblo está encadenado porque ha sido convencido o se ha autoconvencido de que debe renunciar o ceder su racionalidad, ha asimilado como propia la negación de la libertad de pensar.

En el vértigo de la Reivindicación Fichte acelera los argumentos que deshacen e impugnan la dominación despótica, analizando un abanico de posibilidades. Los príncipes y sus satélites, además de no ser más sabios y de carecer de autoridad para definir la felicidad del pueblo, ${ }^{17}$ tampoco se pueden legitimar ni desde el derecho divino, ni desde la fuerza, ni desde el derecho hereditario. ${ }^{18}$ En primer lugar, no se legitiman por derecho divino no sólo porque el príncipe no equivale a Dios, o porque Dios no se expresa únicamente en el príncipe, o porque forman parte del pasado los tiempos en que se usaba a Dios para justificar la servidumbre bestial y el trato de las personas como cosas o propiedades del príncipe; no se justifican de este modo, ante todo, porque Dios se manifiesta en el «sello divino» que cada ser humano lleva en sí mismo. ${ }^{19}$ Este sello y reflejo de la

\section{FSW VI 7-9, RLP 9-12.}

\section{FSW VI 10-11, RLP 12-14.}

19. Al igual que la "espina que moviliza» o la «chispa divina» que tratamos abajo, el "sello divino» (FSW VI 10, RLP 13; o el «rayo divino en nosotros» en Versuch einer Kritik aller Offenbarung, § 2, FSW V 30, trad. cast. V. Serrano: Ensayo de una crítica de toda revelación. Madrid: Biblioteca Nueva, 2002, p. 186; también en Beitrag zur Berichtigung der Urtheile des Publicums über die französiche Revolution, FSW VI 40; o la "voz de nuestra conciencia» en el citado Versuch § 8, FSW V 88, trad. p. 94) no debe tomarse como un simple giro literario, sino como lo que es, un argumento crucial en favor de una razón inmanente, accesible a cada Yo, imposible de ser apropiada o arrogada en exclusividad. Este argumento se condice tanto con la idea de Dios como ser racional-moral (Versuch § 3, FSW V 51-52, trad. 67-69; Versuch § 11, FSW V 121, trad. 123), como con su definición de "orden moral del mundo» (Ueber den Grund unseres Glaubens an eine göttliche Weltregierung, FSW V 185-186; trad. cast. J. Rivera de Rosales: «Sobre el fundamento de nuestra fe en un gobierno divino del mundo», en La polémica sobre el ateísmo: Fichte y su época. Madrid: Dykinson, 2009, pp. 144-145). En este sentido, no hay que minimizar la sacralidad del ser humano, tal como señala Fichte en Grundlage des Naturrechts nach Principien der Wissenschaftslehre (en adelante: GNR), § 6.Cor., GA I/3

Thémata. Revista de Filosofía $\mathrm{N}^{\circ} 56$ (2017) pp.: 91-110. 
razón en cada uno es lo que habilita la condición de estricta igualdad entre todos los seres humanos, independientemente del rango jurídico-político o de la condición social. En segundo lugar, los príncipes y sus acólitos tampoco se legitiman mediante la fuerza, porque la fuerza no procede sino de los gobernados. Aunque en este caso Fichte presupone y concibe al pueblo de modo unitario - como una sola fuerza y no una diversidad de fuerzas en pugna, algunas de las cuales podrían servir al status quo-, el cuestionamiento de la legitimidad interpela al conjunto. En última instancia, la escisión gobernantes-gobernados signada por el ejercicio unilateral de la fuerza para mantener un orden de cosas injusto representa una composición forzada, es decir, un engendro de sociedad donde el antagonismo tiene que agudizarse y resolverse por la revolución o la reforma. De una o de otra manera, si de la órbita del príncipe se sustraen los brazos de los gobernados, entonces el poder se ejecuta sobre el vacío, y el cuestionamiento de la legitimidad queda en evidencia. En tercer lugar, el derecho hereditario tampoco ofrece sustento, argumenta Fichte, pues ¿de qué fuente obtuvo el derecho el primero de la serie? Y si el primero carece de legitimidad, lo mismo sucede en todos los miembros restantes. No se trata de un argumento empírico o histórico, sino de una impugnación filosófica: la regresión al infinito, a la noche de los tiempos, o a la tradición de la antiquísima injusticia, no ofrecen absolutamente ningún sustento racional. No se condena al Yo a la dependencia mecanicista-despótica de una causa remota, inaccesible e injustificable racionalmente, sino sólo si se obtiene de este Yo la claudicación espiritual. Así como en la Doctrina de la Ciencia el Yo no procede regresivamente al infinito, sino que se pone a sí mismo por sí mismo, en este punto la razón no obedece a dictámenes de una instancia trascendente que aniquila su autonomía, sino que a lo sumo y por debilidad se cree puesta y no alcanza a reconocerse como poniente. Pero en cuanto despierta y descubre el sello divino -esto es, ni bien el pueblo asume como propia la libertad de pensamiento-, la razón (el Yo) no admite más que lo que ella misma consiente.

Ahora bien, en un esquema donde el Yo, la razón o la ley moral, son inalienables, el desafío pareciera residir en la capacidad individual para elevarse a esta huella divina, y entonces la intersubjetividad quedaría en un segundo plano. Semejante fachada, no obstante, se revierte en una consideración más profunda y detenida. Una vez impugnados los mecanismos de legitimación jurídica del despotismo, Fichte se dispone a mostrar el único procedimiento posible de justificación racional de la autoridad, para

383, trad. cast. J. Villacañas, F. Oncina y M. Ramos: Fundamento del derecho natural según los principios de la Doctrina de la Ciencia (en adelante: FDN). Madrid: Centro de Estudios Constitucionales, 1994, p. 170; ni la luz que se proyecta y refleja en cada ser racional que Fichte retoma en Die Wissenschaftslehre (1804), FSW X 118-121.

Thémata. Revista de Filosofía $\mathrm{N}^{\circ} 56$ (2017) pp.: 91-110. 
lo cual presenta la distinción entre derechos alienables y derechos inalienables. Esta distinción presupone la concordancia con la ley moral, ${ }^{20}$ o con la facultad auto-legislativa de la razón que caracteriza a cada hombre, y sólo desde ella se podrá deducir la transferibilidad del derecho que sustenta a la autoridad:

El hombre no puede ser heredado, ni vendido, ni regalado; no puede ser propiedad de nadie [...]. Lleva profundamente en su corazón una chispa divina que lo eleva sobre la animalidad y lo hace conciudadano de un mundo cuyo primer miembro es Dios - su conciencia (Gewissen). Ésta lo gobierna absoluta e incondicionalmente a querer esto y no aquello, y eso [sucede] libremente y desde su propio movimiento, sin ninguna coacción exterior. El hombre debe obedecer esta voz interior [...]. Por tanto, ningún extraño puede mandar sobre él; el hombre mismo tiene que hacerlo según la ley que se da en él. El hombre es libre y tiene que permanecer libre. Nada puede gobernarlo, salvo la ley que está en él, porque es su única ley; y cuando se deja imponer otra, contradice esta ley, y se aniquila la humanidad. ${ }^{21}$

El hombre no es cosa, y en ello reside la diferencia capital con el dogmatismo / despotismo; el hombre es chispa divina, actividad libre cuyo fundamento último e inmanente, Dios o la conciencia moral, se erige en instancia soberana de (auto-)legislación y (auto-)referencialidad. El hombre se sustrae a cualquier tipo de ley o de relación que lo convierta en algo sometido. Cualquier signo de una ley que lo determine significa la anulación de aquello que lo separa de los animales, la libertad. Pero si el hombre no ha de obedecer más que a su voz interior, entonces el orden

20. Sobre la deducción indirecta del derecho desde la ley moral, véase Beitrag, FSW VI 60-61. En Grundlage des Naturrechts, en cambio, Fichte abandona esta deducción y establece una distinción férrea entre derecho y moral (GNR Ein., GA I/3 320-323, FDN 110-112), que los comentadores intentan explicar y conciliar: F. Neuhouser: «Fichte and Relationship between Right and Morality", en D. Breazeale - T. Rockmore (editores): Fichte: Historical Contexts / Contemporany Controversies. New Jersey: Humanities Press, 1994, p. 172; R. Schottky: Untersuchungen zur Geschichte der staatsphilophischen Vertragstheorie im 17. und 18 Jahrhundert. Ámsterdam / Atlanta: Rodopi, 1995, p. 261; V. Waibel: «On the Fundamental Connection between Moral Law and Natural Right in Fichte's Contribution (1793) and Foundations of Natural Right», en D. Breazeale - T. Rockmore (editores): Rights, Bodies and Recognition. Hampshire: Ashgate, 2006, pp. 54, 57.

21. FSW VI 11-12, RLP 14-15. Esta absolución del hombre se condice con la consideración del Selbst o forma originaria del Yo puro en Beitrag, FSW VI 58-59, y en Bestimmung des Gelehrten, GA I/3 28-30 (trad. cast. F. Oncina y M. Ramos: Algunas lecciones sobre el destino del sabio. Madrid: Istmo, 2002, pp. 40-41, 44-47). Sin embargo, según J. Villacañas en esta última obra Fichte deja de lado la subjetividad individual y refiere a una subjetividad genérica, aseveración que resulta acertada para Beitrag, pero no refleja la intersubjetividad que en este artículo tratamos de mostrar en la Reivindicación. Villacañas, J.: «La experiencia de la revolución en Fichte: de la Ilustración a la teocracia», en E. Bello (editor), Filosofía y revolución. Murcia: Universidad de Murcia, 1991, pp. 203-204, 206, 209.

Thémata. Revista de Filosofía №56 (2017) pp.: 91-110. 
político sería una quimera y sólo se podría proyectar una suerte de orden moral basado en una presunta armonía preestablecida. Si se lo toma como una pieza entera e independiente, el pasaje citado pareciera anclarse en un individualismo inconciliable a nivel social.

Sin embargo, lo que está en cuestión no es cualquier ley, sino la máxima ley, la ley primera. Por ende, toda otra ley que no se ubique por encima ni a la altura de la ley moral primera y sea coherente con ésta, bien puede ser aceptada. Del mismo modo, el querer y la influencia exteriores también pueden acompañar el gesto de auto-legislación; e incluso la coacción, que indica un forzamiento, en la medida en que reconduce al ejercicio de la libertad, no sería sino un poner en concordancia el querer esto o aquello con la ley moral, una manera de despejar el mensaje turbio de la voz de interior. En otras palabras, la ley soberana no implica un encapsulamiento en la individualidad, sino la consagración de la razón como instancia máxima desde la cual se legitima el orden político; no implica que toda acción del otro lleve a la aniquilación de la voluntad de uno, sino por el contrario, que la acción del otro bien podría vitalizar la auto-actividad; no implica, en fin, un cierre sobre sí del querer o de la voluntad, sino la necesidad de articular las leyes positivas bajo el signo de la voluntad una y coherente. No se trata de un esquema cerrado, sino de un esquema que interpela a la individualidad para mostrar que todo orden jurídico-político presupone siempre algún tipo de consentimiento, y que el parámetro de medida de semejante querer (por acción u omisión) sólo proviene de la autolegislación del conjunto.

En efecto, si el derecho se sigue de lo que la ley moral no prohíbe, no gana con ello suficiente contenido ni fuerza, sino apenas una delimitación formal. Pero hay condiciones -prosigue Fichte- sin las cuales no existiría ninguna ley; por ejemplo, la libertad y la personalidad..$^{22}$ Éstas son las condiciones que obligan a analizar la concordancia de las leyes positivas con la ley moral fundamental. Por una parte, las condiciones por las cuales es posible actuar en conformidad y según el deber configuran los derechos inalienables. La facultad auto-legislativa de la razón constituye el pilar de estos derechos intransferibles. Por otra parte, los derechos que conforman el ámbito de lo permitido sí son alienables, aunque sólo voluntariamente, pues de lo contrario contradicen la ley primera, y entonces una ley secundaria y derivada se entrometería en el lugar soberano. (Aquí se comprende cabalmente por qué el despotismo es imposible de compatibilizar con este esquema: porque impone sin consentimiento y unilateralmente una ley arbitraria que, aun siendo racional, está impugnada de raíz en el dispositivo mismo que repele cualquier articulación con la voluntad de los goberna- 
dos). La distinción entre derechos alienables e inalienables se armonizaría con la distinción entre acciones externas e internas, respectivamente. Mientras los primeros se pueden ceder, condicionar o negociar mediante el contrato, los segundos permanecen sustraídos de la legalidad. ${ }^{23}$ Luego cabe preguntarse si la distinción agota la correspondencia simétrica de cada uno de los ámbitos, es decir, si todo lo alienable concierne a lo externo y lo intransferible a lo interno; y cabe preguntarse, además, si ambas esferas se conciben independientemente una de la otra. De estas dos cuestiones depende la interpretación de la intersubjetividad en Fichte.

En una primera instancia, la exposición de la Reivindicación enfatiza los ámbitos separados e independientes. La negociación del contrato que funda la sociedad civil y que culmina en la definición del poder ejecutivo y del orden institucional mismo, pareciera basarse exclusivamente en las acciones exteriores transferibles, como si constituyeran una entidad aparte. Sin embargo, estas acciones jamás se enajenan totalmente, en cuanto que, a pesar de la transferibilidad, siguen siendo fruto de la voluntad y no se escinden de ella; en este sentido, las acciones externas tienen que conservar la coherencia con la autonomía y la personalidad. Por eso la ley externa no puede contradecir la ley suprema, y por eso lo que diferencia a un soberano legítimo de un soberano ilegítimo concierne precisamente a la transferencia del poder desde los gobernados y como un acto de consentimiento, mientras que el último se arroga el poder unilateralmente y sin referencia alguna a las restantes voluntades. Por tanto, en el contrato de «todos los miembros con uno, o de uno con todos», ${ }^{24}$ donde la horizontalidad y la verticalidad se despliegan conjuntamente, «la legislación civil es válida para mí sólo porque la acepto voluntariamente [...] y porque me doy a mí mismo la ley». ${ }^{25}$ En la fundación de la sociedad civil, en el nombramiento del príncipe y en la definición del Estado, lo transferible y lo intransferible -lo que justifica la distinción entre gobernantes y gobernados- mantienen la conexión a través de la voluntad.

El tema de la separabilidad o inseparabilidad de lo externo y lo interno cobra una peculiar relevancia en torno de la libertad de pensamiento y la libertad de expresión. En efecto, si lo que caracteriza al hombre respecto de los animales consiste en que puede pensar libremente y reconfigurar según su querer el mecanismo ciego de asociación de ideas, la realización de esta facultad no atañe sólo al ordenamiento o a la dirección de las representaciones (lo que revela que la pasividad es una cara o aspecto

23. FSW VI 12, RLP 15-16.

24. FSW VI 13, RLP 16-17.

25. FSW VI 13, RLP 17.

Thémata. Revista de Filosofía N56 (2017) pp.: 91-110. 
de la actividad), ${ }^{26}$ sino también a las acciones que se siguen de, o se enlazan con, o presuponen tales ideas. No se trata de una facultad meramente ideal, sino también real, porque pensar y actuar van de la mano. Mientras el pensar y el actuar en los animales se dan como sucesiones mecánicas, en el ser humano se explican desde la soberanía de la libertad:

la exteriorización (Aeusserung) de la libertad en el pensar, así como la exteriorización de la misma en el querer, es parte intrínsecamente constitutiva de su personalidad; es la condición necesaria únicamente bajo la cual puede decir: yo soy, soy un ser autónomo. Esta exteriorización, ciertamente tanto como aquélla, le asegura su conexión con el mundo espiritual y lo lleva a la concordancia con él. ${ }^{27}$

La libertad no se circunscribe sólo al pensar, sino que involucra su manifestación, al igual que el querer correlativo. Y esta manifestación forma parte de la auto-constitutividad del sujeto, de la personalidad como derecho inalienable, del ponerse a sí mismo y concebirse como ser autónomo. Además, la manifestación, tanto del pensar como del querer, sitúa al sujeto en conexión y concordancia con el mundo espiritual compartido, es decir, lo relaciona y articula con otros seres racionales. Por consiguiente, la libertad de pensamiento y la libertad de expresión son inseparables y se legitiman desde la autoformación del sujeto en interacción recíproca. En coherencia, Fichte protesta por el permiso para pensar sin el correlativo permiso para "comunicar nuestros pensamientos», ${ }^{28}$ pues se trata de un formalismo: como lo primero es imposible, la censura cae sobre lo segundo. Pero si la libertad de pensamiento y de expresión son inescindibles, el formalismo caduca: no tiene ningún sentido que se permita pensar y se

26. Contra la visión tradicional y dogmática de la verdad, en la Reivindicación Fichte expone una concepción teórica y práctica de la verdad, según la cual el conocimiento objetivo se funda en la "espontaneidad más pura y más libre" (FSW VI 19, RLP 25) que debe producir los conceptos sobre las cosas en base a conceptos espirituales. Se trata-como en el $\S 2$ de Versuch einer Kritik aller Offenbarung (FSW V 21-22, trad. cast. 179-180)- de la primacía de la práctica que funda la teoría, donde la percepción de lo dado -el momento, por así decir, más pasivo- se explica desde la actividad, tal como resultará evidente en Grundlage der gesammten Wissenschaftslehre $\S \S 4-5$, en especial desde el comienzo de la dialéctica entre actividad y padecer (GA I/2 293 ss.) y la reunión del intuir y producir en la imaginación (GA I/2 370, 377 ss.), hasta la explicación de la actividad objetiva mediante el esfuerzo o tendencia (Streben, Tendenz) (GA I/2 397), que concluye en que: "la razón misma no puede ser teórica, si ella no es práctica; ninguna inteligencia en el hombre es posible, si no hay en él una facultad práctica" (GA I/2 399). Conocer objetos, entonces, para Fichte significa orientar la actividad hacia ellos, o dejar de actuar en un sentido transformador para actuar en un sentido contemplativo/perceptivo.

27. FSW VI 14, RLP 18.

28. FSW VI 15, RLP 19.

Thémata. Revista de Filosofía №56 (2017) pp.: 91-110. 
prohíba la expresión. Así, lo que realmente está en juego aquí es la libertad de exteriorizar las ideas, la comunicación con el otro, y el nivel de profundidad y compromiso que implica el compartir. Si la manifestación resulta inherente y constitutiva de la personalidad, entonces no significa un derecho transferible, sino inalienable. Y si renunciar a la expresión equivale a renunciar a la libertad, en la propia constitución del sí-mismo se halla el manifestarse al otro y del otro.

En cierta medida la relación intersubjetiva ya está presupuesta en el contrato, y lo que pareciera deducirse de la libertad encerrada en el ser racional individual, se revierte en el proceso: al presentar la libertad de pensamiento como correlativa de la libertad de expresión, y al enfatizar que ésta constituye la propia personalidad, Fichte neutraliza y reconfigura el individualismo de partida. El ser racional que descubre en sí la ley moral, que se pone a sí mismo y que contiene una libertad inalienable, en una segunda consideración se encuentra necesariamente relacionado con otros seres semejantes. Y esta segunda consideración no es derivada, sino constitutiva de la personalidad. La clave para no interpretar el desplazamiento como una contradicción o bifurcación, ni como una instancia subordinada a la otra, reside en que lo interior y lo exterior (o la actividad ideal y la real) son dos caras de un mismo proceso. Por ende, la esencialidad misma de la expresión se entrelaza con el compartir intersubjetivo, con una comunicación (Mittheilung) que se puede desenvolver tanto en términos conflictivos de obstaculización o estorbo (de ahí la necesidad de un contrato que determine las esferas de libertad de cada uno en el marco de los derechos transferibles), como en términos armónicos del «dar y recibir» (Geben und Nehmen) basados en el querer. La relación intersubjetiva descansa en la voluntad y el consentimiento. ${ }^{29}$

Ahora bien, si el derecho a la comunicación libre se deduce del permiso (y no del mandato) de la ley moral e involucra a acciones exteriores, podría ser alienable; y si además depende de la voluntad de las partes, entonces llevado al extremo se suscitaría el caso -especula Fichte- de una renuncia deliberada del compartir. Aunque la prescindencia de la relación intersubjetiva sea inverosímil (porque se asimila a la auto-anulación de la voluntad, como el querer esclavizarse), Fichte la admite como hipótesis: el derecho a renunciar al derecho a la comunicación contiene necesariamente la renuncia al dar y recibir, y así por ejemplo la persona se tendría que encapsular en sí ante el hambriento y dejarlo morir, o «querría cortar el más bello vínculo que une a los hombres con los hombres, que hace desbordar un espíritu en otro espíritu». ${ }^{30}$ La retórica antecede al razonamiento,

29. FSW VI 15, RLP 20.

30. FSW VI 16, RLP 21. A diferencia de este texto, en Beitrag «el más bello vínculo de reu-

Thémata. Revista de Filosofía N56 (2017) pp.: 91-110. 
la apelación al corazón a los motivos que tornan imposible prescindir de la relación con el otro. De todos modos, quebrar el vínculo que encadena y compromete, que reconfigura a los espíritus en un flujo común, significa encapsular al sujeto-átomo y colocarlo en una primacía ficcional para reducir la sociedad a mero producto instrumental sometido a la lógica egoísta. En consecuencia, por si acaso la retórica del corazón no funcionara, Fichte expone finalmente el razonamiento:

El derecho a recibir todo aquello que sea utilizable para nosotros es una parte constitutiva de nuestra personalidad; pertenece a nuestra destinación utilizar libremente todo aquello que está ahí para nuestra formación espiritual y moral [...]. Una de las fuentes más ricas de nuestra instrucción y formación es la comunicación de un espíritu a otro. No podemos renunciar al derecho de recoger lo que proviene de esa fuente, sin renunciar [a la vez] a nuestra espiritualidad, a nuestra libertad y personalidad. ${ }^{31}$

La contracara necesaria del derecho a recibir es el dar, y la imposibilidad de prescindir de este intercambio, el más digno de los intercambios, se explica desde una concepción de la subjetividad que, si se enajena de su destinación y de su formación espiritual, quiebra en sí la personalidad. Lejos de la autosuficiencia, el sujeto atomizado pierde aquello que lo caracteriza y distingue de los animales, y deviene sujeto a medias, mera fuerza aplicada al dominio de la naturaleza. ${ }^{32}$ La relevancia del compartir espiritual se explica desde un presupuesto que Fichte desarrolla posteriormente, en el Fundamento del derecho natural, y que no obstante opera en el pasaje citado: el individuo es un producto natural sumamente incompleto, que sólo se termina de formar mediante la cultura. ${ }^{33}$

La artificialidad de la renuncia a la relación intersubjetiva indica una concepción de la subjetividad que se realiza mediante el otro y que sin

nión» (FSW VI 146) que conjunta espiritualmente en la comunicación de la verdad se mantiene subordinado al individualismo, y lo mismo sucede con el vínculo estatal y legal (FSW VI 62, 81-82). De ahí la recepción tan desfavorable que tuvo Beitrag en los principales filósofos de la época: Maimon, Kant, Erhard, Reinhold, etc. Sobre este tema: F. Oncina, «Maimon y Fichte: una interpretación postkantiana de la filosofía práctica del criticismo», en J. Muguerza y R. Rodríguez Aramayo (editores): Kant después de Kant. Madrid: Tecnos, 1989, p. 398; también en "La recepción de la Crítica del juicio...» cit., pp. 206 ss. Véase asimismo Rampazzo Bazzan, M.: «"Kant” contro Kant nella Dottrina del diritto di Fichte», en Akten des XI Internationalen Kant-Kongress: Kant und die Philosophie in weltbürgerlicher Absicht, Bd. 5. Berlín: W. De Gruyter, 2013, p. 833.

31. FSW VI 16-17, RLP 21-22.

32. La distinción alcanzará su clímax madurativo en GNR § 17.Cor., GA I/4 19-20, FDN 272, esto es, en el contraste entre el hombre aislado y el ciudadano enlazado estatalmente.

33. GNR § 3.Cor., GA I/3 347, FDN 133-134; GNR § 6, GA I/3 379 ss., FDN 166 ss.

Thémata. Revista de Filosofía №56 (2017) pp.: 91-110. 
el otro no podría constituir su propia personalidad, es decir, una perspectiva relacional donde el otro, lejos de representar un obstáculo, significa una condición necesaria para el desarrollo del sí-mismo. Como señalamos, de la comprensión de lo interno y lo externo y de su presunta simetría con lo alienable y lo alienable depende la concepción de la intersubjetividad: si uno y otro persisten en la separación, la relación intersubjetiva aparece como un momento subordinado a las subjetividades autosuficientes. Pero no es éste el planteamiento de Fichte. El modelo de sociedad donde los átomos compiten bajo la égida del cálculo egoísta y donde los otros son meros medios para la consecución de los fines propios, no se suscita aquí, porque Fichte neutraliza y soslaya absolutamente el presupuesto de ese modelo según el cual la relación implica una carga, un obstáculo o turbación, un medio a resolver instrumentalmente. Al comprometer la propia personalidad, el otro ya está encadenado al sí-mismo, y éste no se podría explicar sin aquél, porque no se puede explicar sin el más bello vínculo que lo enlaza a la espiritualidad y lo coloca en la senda de la formación. Y al concebir de este modo la intersubjetividad -esto es, no como un producto o concesión del individuo para obtener ulteriores beneficios, ni como una instancia subordinada e instrumental, sino como esencialmente constitutiva de la subjetividad misma-, Fichte encuentra el punto de reconciliación de lo interno y lo externo, pensamiento y manifestación, y lo expone en términos de entramado relacional.

En otras palabras, si el sujeto pudiera renunciar a la comunicación y al vínculo, sin por ello perder su condición espiritual ni la libertad -y, por ende, separando tajantemente el pensar y la exteriorización-, entonces la intersubjetividad sería sólo un grado secundario de realización sometido a un cálculo utilitario personal. Ante semejante autosuficiencia constitutiva, este sujeto sólo habría de relacionarse por conveniencia y en un espacio relacional extra-subjetivo que se condice con la transferibilidad y con la consiguiente apropiación despótica de ese mismo espacio. Pero, dado que el intento argumentativo de Fichte tiene como motivación explícita defender la libertad de pensamiento en conjunción con la libertad de expresión frente a las pretensiones del príncipe y sus satélites, su estrategia consiste en sustraer el espacio relacional de esta órbita alienable y concebirlo como intrínsecamente relacionado a la constitución de la propia subjetividad.

Luego, la argumentación se complementa con la legitimación del poder soberano, donde la misma subjetividad, incapaz de realizarse renunciando a querer relacionarse con el otro, es a la vez la que se unifica en el entramado contractual y nomina al representante ejecutivo de la voluntad Una, es decir, consiente la formación de la sociedad civil, del Estado y de los representantes del poder común. La unificación no sucede al estilo de un sacrificio que el sujeto tiene que conceder, como si todo lo que está fuera

Thémata. Revista de Filosofía $\mathrm{N}^{\circ} 56$ (2017) pp.: 91-110. 
de él le correspondiese o fuese su propiedad natural (y tuviera que renunciar a eso), sino al punto de pensarse a sí mismo en relación necesaria con otros y, por lo tanto, intrínsecamente ya (auto-)limitado y delimitado en una esfera de libertad. Se trata de una delimitación que bien se sigue del relacionarse voluntario, del aceptar la importancia de esa relación para definir la propia subjetividad, y de la misma delimitación que repugna la institución de un poder unilateral desligado de los compromisos recíprocos. El mismo querer que no puede no querer comunicarse con el otro es el que legitima al representante del poder soberano (el legítimo) en confrontación con el esquema despótico (ilegítimo).

En suma, la estrategia de Fichte tiene sentido y vigor sólo si se concibe la subjetividad como formando parte de un entramado relacional, pues de lo contrario se convalida, junto con la individualidad encapsulada y dispuesta a absorber la otredad como suya, la imposición de un príncipe desvinculado de lo social e irresponsable de sus decisiones. Aunque Fichte desplegará esta lógica relacional con mayor consistencia y completitud en Algunas lecciones sobre la destinación del sabio ${ }^{34}$ y en el Fundamento del derecho natural, ${ }^{35}$ en la Reivindicación ya ofrece los elementos básicos y cierta conjugación de los mismos, quizás eclipsados por el problema de la libertad de expresión.

\section{Lo jurídico y sus aristas}

El contexto argumentativo de la Reivindicación ofrece todo un flanco, el jurídico, desde el cual pivotea la libertad en sus diferentes ramificaciones, y sin el cual el simple descubrimiento de la ley moral o de la razón quedaría encerrado en el plano meramente ideal. Este elemento clave deja en claro que la primacía moral, si no se realiza en la práctica, deviene en un proceso formal que contrasta tanto con el fermento revolucionario como con el reformismo gradual, es decir, con la exhortación del Fichte-in-

34. El dar/recibir en Bestimmung des Gelehrten: GA I/3 41, 44-45; trad. cit. pp. 82-83, 90-93. Como señalamos, en esta obra Fichte parte de la definición de sociedad como agregado de individuos (GA I/3 27, trad. 38-39), pero desplaza la definición hacia el aspecto relacional (GA I/3 34, 37; trad. 62-63, 68-69) y concluye con la exaltación mecanicista (GA I/3 41, trad. 84-85) y organicista (GA I/3 49, trad. 102-103) del vínculo social-recíproco.

35. En el ya citado Corolario de GNR § 3 Fichte recupera la interacción recíproca, el dar/recibir conocimientos, como aquello que distingue al ser humano del resto de los seres y que desemboca en la conformación de un mundo compartido: GA I/3 348, FDN 134-135. También en GNR § 6, GA I/3 374, FDN 160-161. En Das System der Sittenlehre va incluso más allá y coloca la teoría de la verdad (que en la Reivindicación se encuentra en FSW VI 18-19, RLP 24-25) bajo la órbita de la comunicación recíproca: § 18, FSW IV 245-247, trad. cit. pp. 276-277.

Thémata. Revista de Filosofía №56 (2017) pp.: 91-110. 
telectual que incita al pueblo dormido y lo insufla de las herramientas necesarias para la transformación del espacio social, jurídico y político. En efecto, la argumentación detallada contra las pretensiones de legitimación del despotismo, que constituye el marco vertebrador de esta obra, no sólo apuntala la relevancia de la problemática jurídico-política, sino también direcciona hacia ella la dimensión moral, pues de lo contrario la libertad de pensamiento se resolvería por sí sola. ¿De qué serviría el librepensamiento carente de expresión?

La libertad de pensamiento, considerada independientemente de la libertad de expresión, deja de representar un problema, dado que ninguna intervención externa puede apagar la chispa divina, salvo la auto-anulación voluntaria. Pero si este acto paradójico significa a la vez la auto-afirmación en la aniquilación, entonces el Yo pasivamente sometido contiene en sí la posibilidad de revertirse en actividad transformadora, desenvolviendo en la práctica el querer y el pensar. Y en la práctica (de ahí la no casual alusión a Rousseau) el hombre se encuentra esclavizado, corporal y espiritualmente. Si esta discordancia fuera sólo un problema moral, Fichte se podría entregar sin más al clima de un espacio público servil al poder establecido. Sin embargo, lejos de desentenderse del asunto, Fichte afina los conceptos para mostrar que pensamiento y expresión son dos caras inseparables de una misma actividad. En consecuencia, la distinción entre derechos intransferibles y derechos transferibles adquiere sustancia y profundidad en la medida en que al mismo tiempo se observa la conexión entre lo interno y lo externo. La cuestión no reside en los derechos que por definición son inalienables, sino en cuáles de los alienables son inalienables; en otras palabras, la cuestión no es moral, sino jurídica. Del mismo modo, todo ordenamiento social y jurídico que aspire a ser legítimo y concordante con la racionalidad no sólo tiene que conjugarse con las condiciones intransferibles, la libertad y la personalidad, sino también con aquello que posibilita tales condiciones. Por ende, lo que en una primera consideración parece circunscribirse al sujeto, luego se revela en un tejido de relaciones jurídicas. La espiritualidad, el enlace más bello, el intercambio más digno, la comunicación, el compartir, el dar y recibir, no son elocuencias retóricas; son manifestaciones de un vínculo y compromiso intersubjetivo sin el cual la persona no podría ser lo que es. Este vínculo constitutivo no contradice en absoluto, sino que por el contrario sustenta y potencia la personalidad y la libertad, focalizando al sujeto en un enlace jurídico.

La persona sola, abstraída y esterilizada de todo influjo social, aunque se eleve a la racionalidad, se asemeja notablemente al déspota. Y se asemeja también a la lógica liberal egoísta que se arroga exclusivamente la potestad de interpretar la ley moral y que somete todo lo externo a la apro-

Thémata. Revista de Filosofía $\mathrm{N}^{\circ} 56$ (2017) pp.: 91-110. 
piación de su arbitrio unilateral. De ahí que tampoco sea casual la ulterior alusión a Rousseau en La destinación del sabio, según la cual quien consiente la esclavitud fuera de sí no es libre. ${ }^{36}$ Tanto el déspota como el egoísta y el servil al orden injusto operan con una lógica de subsunción del tejido social-horizontal para consagrar sus privilegios. Por ende, un igualitarismo no abstracto como el de Fichte no puede aceptar la posición de un particular por encima de los demás, ni conformarse con un reconocimiento formal de derechos sólo a nivel individual y sin ninguna incidencia en lo social.

Lo que emerge en el trasfondo de la Reivindicación, la mutua dependencia de los sujetos o el vínculo que enlaza al sí-mismo y al otro, además de preceder a la intersubjetividad dinámica de las obras posteriores, contiene una arista peculiar. Aunque aquí Fichte no despliegue la temática en todos sus puntos y no aproveche la relevancia de la comunicación para la constitución de la personalidad, deja en siembra un aspecto que nuevamente conduce a Rousseau: el dar/recibir reaparece en el Fundamento del derecho natural en el marco de la relación entre las partes contratantes y el Estado. Mientras Rousseau sostiene que el individuo debe darse totalmente al todo, para Fichte esta entrega sólo puede ser parcial, pues de lo contrario el Estado no tendría ningún compromiso de protección respecto del particular. ${ }^{37}$ Pero lo que parece un argumento liberal se revierte inmediatamente: Fichte explica que el darse total de Rousseau presupone que el individuo, antes del vínculo social-estatal, posee algo para dar, y se distancia de esta idea (más legitimadora de la desigualdad preexistente que del igualitarismo que pretende fundar) ${ }^{38}$ porque en su concepción el individuo antes del vínculo no tiene nada, y entonces el contrato comienza con un recibir. Que el individuo tome posición a partir del vínculo manifiesta que sólo se define como tal en virtud de un entramado de relaciones.

36. GA I/3 39, trad. 80-81.

37. GNR § 17, GA I/4 15 nota, FDN 268.

38. Una idea, por cierto, contraria al interés filosófico e igualitarista del mismo Rousseau, que en virtud de querer neutralizar la transferencia de las desigualdades naturales a la sociedad jurídica, desembocaría según Fichte en un reconocimiento implícito de tales injusticias, y entonces en vez de soslayarlas, tiene que mostrar a las partes por qué les conviene realizar el contrato social. 


\section{Bibliografía}

\subsection{Fuentes, (abreviaturas), traducciones}

J. G. Fichtes sämmtliche Werke (FSW). Hrsg. I. Fichte. Berlín: W. de Gruyter, 1971.

J. G. Fichte - Gesamtausgabe der Bayerischen Akademie der Wissenschaften (GA). Hrsg. R. Lauth, H. Jacob, u. a. Stuttgart: Fromman, 1962 ss.

Fichte, J. G.: Grundlage der gesammten Wissenschaftslehre, en GA I/2 249-451.

: Grundlage des Naturrechts nach Principien der Wissenschaftslehre (GNR), en GA I/3 313-460, I/4 5-165.

: Ensayo de una crítica de toda revelación (trad. V. Serrano). Madrid: Biblioteca Nueva, 2002.

-: Reivindicación de la libertad de pensamiento y otros escritos políticos (RLP) (trad. F. Oncina). Madrid: Tecnos, 1986.

-: Algunas lecciones sobre el destino del sabio (trad. F. Oncina y M. Ramos). Madrid: Istmo, 2002.

: Fundamento del derecho natural según los principios de la Doctrina de la Ciencia (FDN) (trad. J. Villacañas, F. Oncina y M. Ramos). Madrid: Centro de Estudios Constitucionales, 1994.

: Ética (trad. J. Rivera de Rosales). Madrid: Akal, 2005.

: «Sobre el fundamento de nuestra fe en un gobierno divino del mundo» (trad. J. Rivera de Rosales), en J. Rivera de Rosales - O. Cubo (editores): La polémica sobre el ateísmo: Fichte y su época. Madrid: Dykinson, 2009.

\subsection{Bibliografía secundaria}

Baummans, P.: Fichtes ursprünglichen System. Sein Standort zwischen Kant und Hegel. Stuttgart-Bad Cannstatt: Frommann-Holzboog, 1972.

---------: Fichtes Wissenschaftslehre. Probleme ihres Anfangs. Bonn: Bouvier Verlag - Herbert Grundmann, 1974.

Duso, G.: Contradizzione e dialettica nella formazione del pensiero fichtiano. Urbino: Argalia, 1974.

Hunter, C.: Der Interpersonalitätsbeweis in Fichtes frührer angewandter praktischer Philosophie. Meisenheim: Verlag Anton Hain, 1973. 
Janke, W.: "Annerkennung. Fichtes Grundlegungen des Rechtsgrundes", en Kant-Studien, LXXXII, 1992, pp. 197-212.

Lauth, R.: "Le problème de l'interpersonnalité chez J. G. Fichte", en Archives de Philosophie, ${ }^{\circ}$ 25, 1962, pp. 325-344.

Neuhouser, F.: «Fichte and Relationship between Right and Morality», en D. Breazeale - T. Rockmore (editores): Fichte: Historical Contexts / Contemporany Controversies. New Jersey: Humanities Press, 1994, pp. 158-180.

Oncina, F.: «Maimon y Fichte: una interpretación postkantiana de la filosofía práctica del criticismo», en J. Muguerza y R. Rodríguez Aramayo (editores): Kant después de Kant. Madrid: Tecnos, 1989, pp. 369-402.

----------: «La recepción de la Crítica del Juicio en el jacobinismo kantiano: luces y sombras en el camino hacia una teoría democrática de la Ilustración», en R. Rodríguez Aramayo - G. Vilar (editores): En la cumbre del criticismo. Barcelona: Anthropos, 1992, pp. 169-216.

Philonenko, A.: La liberté humanine dans la philosophie de Fichte. París: Vrin, 1966.

: L'Oeuvre de Fichte. París: Vrin, 1984.

Radrizzani, I.: "La Doctrine de la Science et l'Aufklärung", en Revue de métaphysique et de morale, $\mathrm{n}^{\circ}$ 49, 2006, pp. 127-142.

Rampazzo Bazzan, M.: «Persönlichkeit und Denkfreiheit. Ein Beitrag zur Entstehung des Urrechtsbegriffs bei Fichte», en Ch. Asmuth (Hrsg.): Transzendentalphilosophie und Person. Leiblichkeit - Interpersonalität Anerkennung. Bielefeld: Transcript Verlag, 2007, pp. 377-387.

-----: «"Kant" contro Kant nella Dottrina del diritto di Fichte», en Akten des XI Internationalen Kant-Kongress: Kant und die Philosophie in weltbürgerlicher Absicht, Bd. 5 (Hrsg. S. Bacin, A. Ferrarin, C. La Rocca und M. Ruffing). Berlín: W. De Gruyter, 2013, pp. 831-843.

Sauter, M.: "Las luces a prueba" (trad. L. Sanz), en Istor. Revista de Historia, n 19, 2004, pp. 31-48.

----------: Visions of the Enlightenment. The Edict on Religion of 1788 and the Politics of the Public Sphere in Eighteenth-Century Prussia. Leiden: Brill, 2009, pp. 105-140.

Schottky, R.: Untersuchungen zur Geschichte der staatsphilophischen Vertragstheorie im 17. und 18 Jahrhundert. Ámsterdam / Atlanta: Rodopi, 1995. Siep, L.: Annerkennung als Prinzip der praktischen Philosophie. Freiburg/ München: Karl Alber, 1979.

Suhrkamp, 1992. -: Praktische Philosophie im Deutschen Idealismus. Frankfurt:

Villacañas, J.: "Fichte y los orígenes del nacionalismo alemán moderno", en Revista de estudios políticos (nueva época), nº 72, 1991, pp. 129-172.

-: «La experiencia de la revolución en Fichte: de la Ilustración a la teocracia», en E. Bello (editor): Filosofía y revolución. Murcia: Universidad de

Thémata. Revista de Filosofía №56 (2017) pp.: 91-110. 
Murcia, 1991, pp. 197-240.

Waibel, V., «On the Fundamental Connection between Moral Law and Natural Right in Fichte's Contribution (1793) and Foundations of Natural Right», en D. Breazeale - T. Rockmore (editores): Rights, Bodies and Recognition. Hampshire: Ashgate, 2006, pp. 45-58.

Williams, R. R.: Recognition. Fichte and Hegel on the Others. New York: State University of New York Press, 1992.

Willms, B.: Die totale Freiheit. Fichtes politische Philosophie. Köln und Opladen: Westdeutscher Verlag, 1967. 